\title{
EMERGENCY CONTRACEPTION: KNOWLEDGE AND PERCEPTION OF FEMALE UNDERGRADUATES IN THE NIGER DELTA OF NIGERIA
}

\author{
C. I. AKANI, C.E. ENYINDAH and S. BABATUNDE ${ }^{1}$ \\ Department of Obstetrics and Gynaecology; and Department of Community Medicine ${ }^{1}$, College of Health \\ Sciences, Choba, Port Harcourt, Nigeria
}

\author{
Author for correspondence: Dr C. I. Akani \\ Conflict of Interest: None declared
}

\section{SUMMARY}

Objective: To evaluate the knowledge of, and perception of female undergraduates in the Niger Delta of Nigeria towards Emergency Contraception.

Methods: Anonymous self administered questionnaires were applied to randomly selected non-medical female undergraduates of the University of Port Harcourt in May 2005.

Results: Six hundred questionnaires were retrieved out of 610 distributed. The respondents were between 1730 years. Those reported to have ever had sex were $85.3 \%$; most of whom $(98.4 \%)$ have previously used some forms of contraception. About $50.7 \%$ of 600 respondents were aware of emergency contraception; amongst which reports of friends/peers as the source of knowledge ranked highest $(33.55 \%)$. About $88.2 \%$ of those that are aware of Emergency Contraception knew the correct timing. More than half $(57.9 \%)$ did not know correct dosage of the available post-coital pill. While half $(50.7 \%)$ of those having knowledge of postcoital pills agree to the efficacy; only a third (35.53\%) agreed to have actually used it.

Conclusion: The awareness and use of Emergency Contraception amongst female undergraduates in Niger Delta region of Nigeria is low. Prompt education of this group of students in Emergency Contraception should be encouraged with emphasis on available methods and correct timing of use.

Key Words: Emergency Contraception, Knowledge, Perception, Female Undergraduate, Nigeria.

\section{INTRODUCTION}

Unintended pregnancy poses a major challenge to the reproductive health of young adults in developing countries. ${ }^{1}$ With decreasing age of menarche and onset of sexual activity, young people are exposed early to unplanned and unprotected sexual intercourse leading to unwanted pregnancy and invariably abortions. In Nigeria unintended intercourse is the primary cause of unintended pregnancy and induced abortions. ${ }^{2}$ Similarly, the rate of induced abortions is a good indicator of the current state of medical care and family planning in any country. ${ }^{3}$
Emergency contraception is the contraception administered to a woman after unprotected intercourse. In the past it has also been known as postcoital contraception or morning after pills. ${ }^{4}$ Emergency contraception is needed when intercourse is unexpected and without prior contraceptive coverage. Other indications include failure of barrier methods like the slipping or breakage of condoms, and after rape. This emergency contraception may be an effective way to reduce the number of unwanted pregnancies and induced abortions. ${ }^{5}$

Emergency contraception is essentially female driven, so its use and success rests mainly on how women perceive and practice it. Levonorgestrel-only pills and combined oral contraceptives are the most common emergency contraceptive methods available in Nigeria; they can be obtained over the counter from patent medical and pharmaceutical shops. Unconventional techniques of emergency contraception are common among young women in our setting. As much as $75 \%$ of sexually active (14-19) teenage girls have been reported to have some form of perceived contraception device such as laxatives, local potash, "white quinine" and menstrogen pills in the South-West geopolitical zone of the country. ${ }^{5}$

The Niger Delta forms the south- south geopolitical zone of Nigeria. It is the crude oil rich part of the country. In view of the extensive crude oil exploration activities by the expatriates and non expatriates alike, the social activities are very high with attendant sequelae such as unplanned pregnancies, induced abortions and sexual transmitted infections.

The aim of this study therefore was to evaluate the knowledge of, and perception of these vulnerable female undergraduates in the Niger Delta of Nigeria towards emergency contraception.

\section{SUBJECTS AND METHODS}

Anonymous self-administered questionnaires applied to randomly selected female undergraduates students 
(non-medical) of the University of Port Harcourt in May 2005. Questionnaires were piloted on a sample of students in the Rivers State University of Science and Technology, Port Harcourt prior to the main study.

A total of 610 questionnaires were distributed to the students in their hostels. The sample size was calculated. 5.7\% amongst Nigerian adolescents at a precision of $3.5 \%$ set at $95 \%$ confidence level and adjusted for 5\% attrition; sampling was done in two stages, stratified (proportionately) at hostel level and systematically for the rooms. Data were coded and analyzed using the EPI Info 2000 versus 1.0 software package. The instrument explored information on sexual activity, previous use of emergency contraceptives and efficiency of the method used.

\section{RESULTS}

Altogether 600 questionnaires were returned out of the 610 distributed. The respondents were between 17 and 30 years. Most (94\%) of them were single and Christians. The reported to have ever had sex were $85.3 \%(\mathrm{n}=512)$; of those nearly all $(98.4 \%, n=504)$ have previously used some form of contraception; condoms being the most frequently used method $(80.95 \%)$; followed by safe period $(49.60 \%)$ and withdrawal methods (27.38\%). Other unorthodox methods included Guiness (alcoholic beer), illicit gins, herbs/concoctions and douching (Table 1).

\section{Use of Post-Coital Methods}

When the respondents gave answers to questions on previous use of an "after intercourse" preventive method, 200 out of the 512 sexually active students reported using none as shown in table 2. Quinine and post-coital pills ranked highest (112 counts) amongst the items the other 312 had "ever" used. Nearly half $(47.7 \%)$ of those that used a form of "after intercourse" method claimed that pregnancy never occurred. The rest $(52.6 \%)$ admitted the measures were not always successful.

\section{Knowledge of Emergency Contraception Pill}

Regarding knowledge of emergency contraceptive pills (ECP's), $50.7 \%(n=304)$ of the total 600 respondents were aware while the other half $(49.3 \%)$ had not heard of emergency contraceptive pills. Amongst the 304 that were knowledgeable of ECP's, reports of friends/peers as the source of knowledge ranked highest $(33.55 \%)$ followed by sexual partner/spouse $(32.80 \%)$ and health facility/personnel $(18.42 \%)$. When the 304 that were aware of ECP's asked about timing of the use of ECP's, most $(88.2 \%)$ of them said that it should be taken after intercourse, however the remaining $11.8 \%$ divulged incongruous answer such as "before intercourse" and after a missed period.
Of those respondents that have knowledge of ECP's $42.1 \%$ could correctly identify the dosage, but $31.6 \%$ had no idea at all dosage while the rest $26.3 \%$ gave an incorrect dosage.

Table 1 Contraceptive Methods Ever Used

\begin{tabular}{|l|l|l|}
\hline METHOD & FREQUENCY & PERCENT \\
\hline Condom & 408 & 80.95 \\
\hline Safe Period & 250 & 49.60 \\
\hline Withdrawal & 138 & 27.38 \\
\hline Quinine & 94 & 18.65 \\
\hline Andrew Liver Salt & 82 & 16.27 \\
\hline Krest (Soft Drink) & 72 & 14.29 \\
\hline Post Coital Pills & 60 & 11.90 \\
\hline Guiness (Alcohol) & 56 & 11.11 \\
\hline Daily Pills (COCP) & 28 & 5.56 \\
\hline Hers/Concoctions & 22 & 4.37 \\
\hline Douching & 16 & 3.17 \\
\hline Nothing & 6 & 1.20 \\
\hline & &
\end{tabular}

\section{Perception and Use}

While up to half $(50.7 \%)$ of those having a knowledge of ECP's. offered that they agree/strongly agree to its efficiency, $25.8 \%$ disagreed and $26.5 \%$ could not take a stand (were undecided). About two-thirds (64.5\% $\mathrm{n}=108$ ) reported that they had never used them while only about a third (35.53\%) reported that they had actually used them.

Table 2 Rank Ordering of "After Intercourse" Contraceptive Methods Ever Used

\begin{tabular}{|l|c|}
\hline CONTRACEPTION & $\begin{array}{l}\text { COUNTS } \\
\text { (N=512) }\end{array}$ \\
\hline Condom & 200 \\
\hline Quinine & 112 \\
\hline Post Coital Pills & 112 \\
\hline Andrew Liver Salt & 106 \\
\hline Krest (Soft Drink) & 90 \\
\hline Stout (Alcohol) & 90 \\
\hline Hers/Concoctions & 48 \\
\hline Illicit Gin (local hot drink.) & 30 \\
\hline Daily Pills (COCP) & 16 \\
\hline Douching & 4 \\
\hline
\end{tabular}

A ranking order of the sources where they purportedly obtained the pills indicated the "chemist" (patent medicine stores and pharmacies) as the most popular (100/108 counts) which was ten times over the other mentioned sources. Health facility/personnel (12/108 counts), friends (8 counts) and partner (5 counts).

\section{DISCUSSION}

The results from this study revealed that about half $(50.7 \%)$ of the respondents knew about emergency 
contraceptives. However, most of the undergraduates lacked detailed knowledge about the regimen. This finding is similar to a study in Princeton University which showed that while the basic awareness of the emergency contraceptive pill was widespread students lacked detailed knowledge about the regimen.?

The reason for the lack of detailed knowledge on this subject may be linked to the sources of information; majority of the students got to know about emergency contraception from their friends/peers who may not have a good grasp of the subject. Information gap and poor compliance attitudes constitute major constraints in emergency contraception thereby leading to high rate of unwanted pregnancies. ${ }^{8}$ There is a dearth of information and counselling services at the patent medicine stores where most of the pills are dispensed as the study showed, without supervision over the counter. Access to contraceptives through government health institutions is limited to few service points and during morning working hours accounting for why many do not visit them. The private sector with very poor providers' knowledge are therefore burdened with the emergency need for contraception in face of failed condom use, and unprotected act of intercourse which occur within the social or leisure hours of the day.

Demand for emergency contraception is made by the confidentiality the clients anticipate without information or counselling. It is often believed or assumed that the clients are well informed of the product and the method. This information gap remains a cardinal step of failure. ${ }^{9}$

More disturbing is that less than half $(42.1 \%)$ of those who were aware about emergency contraception knew the correct dosage. This is as a result of the dearth of correct information on emergency contraception available in Nigeria. ${ }^{6,8}$ In absence of this requisite information regarding proven emergency contraception, some respondents believed that folk methods such as Quinine, Andrew Liver Salt, Alcohol, Herbs/Concoctions could be used as emergency contraception. A similar finding has been documented by earlier studies in the country. 6

\section{CONCLUSION}

This study shows that the awareness of emergency contraception amongst undergraduates of the Niger Delta region of Nigeria is low; and even amongst those that are aware, majority do not practice it because of dearth of correct information. This is worrisome considering the social activities in this zone of the country, and the fact that most of these undergraduates belong to the age group at risk of unplanned /unintended pregnancy and the age group who mostly use the barrier method of contraception such as condom with its problem- bursting, slippage..$^{10,11}$

To change this, there is a need to educate this group on emergency contraception with emphasis on available methods and correct timing of use. The education process has to be a collective effort of the schools, health facilities, media parents, government and non government organizations. ${ }^{12}$

\section{REFERENCES}

1. Okonofua F.E. Factors associated with Youth and Adolescent Pregnancy in Rural Nigeria Journal and Adolescent. 1995:24(4); 419-438.

2. Emergency contraception in Nigeria. Report of an Exploratory Research Project Lagos. Society for family health 1998: 1-2

3. Bartfan GY. Emergency contraception in clinical practice: Global Perspective. International Journal of Gynaecology and Obstetrics 2000: 70; 49-58.

4. Silvestre L, Bouali Y, Ulmann A. Postcoital Contraception: myth or reality? Lancet. 1991: 338; 39-41

5. Haspels A.A. Emergency contraception: A Review. Contraception. 1994:50; 101-108.

6. Arowojolu A.O, Adekunle A.O. Perception and Practice of Emergency contraception by Post secondary students in South-West Nigeria. African Journal of Reproductive Health. 2000: 4 (1); 56-65

7. Harper C.C. The Emergency contractive pill. A survey of knowledge and Attitude among Student at Princeton University. America Journal of Obstetrics and Gynaecology. 1995; 11; 173-175

8. Aziken E.E, Okonta P.I, Ande A.B. Knowledge and Perception of Emergency contraception among female Nigeria undergraduates. International family Planning Perspectives. 2003; 29 (2); 84-87.

9. Kiragu K, Zabin L.S Contraceptive use among high school students in Kenya. International Family Planning Perspectives. 1995: 21(3); 108113.

10. Brabin L, Kemp J, Obunge O.K, Ikimalo J, Dollimore N, Odu N.N, Hart A.C, Briggs N.D. Reproductive tract Infections and Abortion among Adolescent girls in Rural Nigeria. Lancet 1995: 345; 300-4.

11. UK Family Planning Research Network: Mishap occurring during condom use and the subsequent use of Post coital contraception. Br. J. Family Planning. 1993: 19, 218-220.

12. Ashraf H, McCarthy M. UK Improves Access to “Morning After Pill”.Lancet 2000: 20 (17); 356. 